TRANS · núm. $24 \cdot 2020$

ENTREVISTAS · 503-510

Ricardo San Vicente es un traductor de literatura rusa, ensayista y profesor. En la Universidad de Barcelona impartió literatura rusa antigua, moderna y contemporánea. Ha traducido a numerosos escritores rusos, como Tolstoi, Zóschenko, Shalámov, Bulgákov, Chéjov, Brodski, Dovlatov o Bábel. Ricardo San Vicente fue el primer traductor de Voces de Chernóbil de la escritora bielorrusa, Svetlana Aleksiévich galardonada con el Premio Nobel de Literatura en 2015.

PALABRAS ClaVE: Ricardo San Vicente, Svetlana Aleksiévich, Voces de Chernóbil, literatura rusa traducida.

\title{
Entrevista a Ricardo San Vicente (traductor al español de Voces de Chernóbil de Svetlana Aleksiévich)
}

\author{
KatSIARYNA RUDENIA \\ Universidad de Málaga
}

\section{An Interview with Ricardo San Vicente (the Translator of Svetlana Alexievich's Chernobyl Prayer into Spanish)}

Ricardo San Vicente is a translator of Russian literature, an essayist and a professor. He taught antique, modern and contemporary Russian literature at the University of Barcelona. He translated many Russian authors such as Tolstoy, Zoshchenko, Shalamov, Bulgakov, Chekhov, Brodsky, Dovlatov and Babel. Ricardo San Vicente was the first who translated Chernobyl Prayer, the book written by Belarusian author Svetlana Alexievich, the winner of the Nobel Prize in Literature in 2015.

KEY WORDS: Ricardo San Vicente, Svetlana Alexievich, Chernobyl prayer, Russian literature translated into Spanish. 


\section{INTRODUCCIÓN}

Ricardo San Vicente es profesor, ensayista y traductor de literatura rusa. Nació en Moscú en 1948, hijo de padres vascos que estuvieron exiliados en esa ciudad. Gracias a la amnistía, en 1957 la familia volvió a España. Ricardo San Vicente estudió en el Liceo Francés de Barcelona, también aprendió el francés y el catalán, e hizo el magisterio de August Vidal. En 1979 inició su carrera del traductor. En el año 1987 pasó a ser profesor de la Universidad de Barcelona, donde impartió literatura rusa antigua, moderna y contemporánea, continuando su labor sobre traducciones literarias.

San Vicente no solo se ha dedicado a la traducción sino, también, a la edición y divulgación de la literatura rusa, en paralelo a su actividad docente. Entre sus traducciones se encuentran obras de Tolstoi, Zóschenko, Shalámov, Bulgákov, Chéjov, Brodski, Dovlatov y Bábel y en especial para nuestro interés de Svetlana Aleksiévich. Las traducciones de Ricardo San Vicente se caracterizan por su rigor tanto en lo que respecta a la realidad y la lengua de origen como a su sensibilidad en el traslado del estilo de los diversos autores que ha trabajado. Una de sus grandes aportaciones de traducciones ha sido el ciclo completo de relatos de Varlam Shalámov, los Relatos de Kolimá, editados por Minúscula. Ha escrito numerosos artículos en la prensa española y presentaciones de sus propias traducciones y de las de otros traductores. ${ }^{1}$

Ricardo San Vicente, a su vez, ha sido el primero en traducir al español, en 2006, la obra de Aleksiévich Voces de Chernóbil. Mediante esta entrevista buscamos acercarnos a la labor de su traducción para entender las dificultades y los

I https://www.ub.edu/web/ub/es/menu_eines/noticies/2018/05/063.html pormenores de esta obra traducida y así mismo dar entrada a cómo analizar las maneras con las que han sido tratadas las realidades rusas en el texto y se han involucrado con ellas las estrategias a los efectos de su traducción.

Es importante, según nuestro juicio, dar una nota sobre la escritora bielorrusa Svetlana Aleksiévich, y así mismo incluir ahora una breve noticia sobre su obra. Aleksiévich en actualidad ya ha sido mundialmente reconocida como una escritora de relieve, gracias, por una parte, a la capacidad comunicativa de sus obras, y por otra parte, al carácter innovador de las voces narrativas que utiliza. Galardonada con el Premio Nobel de Literatura en el año 2015, sus obras polifónicas son un monumento al sufrimiento y al coraje humano de nuestro tiempo. En concreto, el libro que tratamos, Voces de Chernóbil, recoge una gran información sobre esa catástrofe que la autora extrae de las conversaciones con más de quinientas personas, todas testigos de aquella tragedia, entre las cuales se encuentran bomberos, personas que se ocupaban de la radioactividad, políticos, físicos, y otros residentes en la zona contaminada, así como familiares de los fallecidos. La obra impresiona al lector por el fuerte impacto que ejerce el tono de oralidad que presenta y las intensas emociones que se desprenden de los relatos de los entrevistados. La escritora no construye una realidad de los hechos, sino una visión de aquel tiempo y la manera de imaginarla a través de la lectura: ¿Cómo vivían? ¿En que creían?.. De esta forma, nos presenta a su país bajo el prisma de la gente que vivió en aquella época. Por ello, sus libros se convirtieron en crónicas y en una especie de historia narrada de casi diez generaciones, que ella investigó acompañada de las cuales ha seguido su camino creativo.

Según Ricardo San Vicente, es importante el hecho de que Alexievich recoge testimonios personales. Los protagonistas varían por edad, pro- 
fesión, vivencia del conflicto y de la tragedia. A su vez, piensa el traductor, el lector se da cuenta de que en su primera obra La guerra no tiene rostro de mujer, el personaje femenino nunca presente en la literatura sobre la guerra; por eso en realidad la autora escribe un libro construido a base de testimonios. Sus temas giran alrededor de lo que Aleksiévich denomina el experimento soviético y en la introducción a su último libro, Tiempo de segunda mano: el fin del hombre rojo, expresa precisamente ese interés por el homo soveticus, y así mismo por las generaciones que se caracterizan mediante esa diferencia y también por las víctimas y testigos de aquel enorme experimento sociológico que fue la Unión Soviética.

La obra Voces de Chernóbil, en palabras de traductor, a su vez, aborda nuevamente un hecho en este caso catastrófico y trágico de gran envergadura social que fue conocido en todo el mundo y que a partir los testimonios de los bomberos, sus esposas, militares, supervivientes, políticos, y además los liquidadores - llamados así porque fueron quienes se ocuparon de limpiar la zona. San Vicente manifiesta también cómo Alexiévich vincula estos temas contemporáneos en la urdimbre de gran fenómeno histórico que fue la Unión Soviética, intentando entender la cultura y la forma de vida que produjo. ${ }^{2}$

Antes de pasar a la entrevista, manifestamos nuestra gratitud a Ricardo San Vicente por su colaboración. La entrevista se realizó por teléfono y después, conservando la forma comunicativa del traductor se transcribió al papel. En la entrevista, como hemos indicado arriba, interesa la labor del traductor más en el sentido práctico y concreto que en el teórico. Para centrar la entrevista, todas las cuestiones que le planteamos se refieren a la obra citada de Aleksiévich Voces de

\footnotetext{
2 https://www.ub.edu/web/ub/es/menu_eines/noticies/2015/entrevistes/sanvicente.html
}

Chernóbil, cuya traducción ha sido valorada en 505 los medios.

\section{Entrevista}

\section{¿Cuál es su relación con el idioma ruso?}

He nacido en Rusia, mis padres eran niños de la guerra de 1936; se fueron a la Unión Soviética y allí se quedaron por varias razones hasta 1956. Nací en 1948 y mi lengua primera fue el ruso, o sea que mi competencia lingüística posterior estaba preparada por la adquisición del idioma en la infancia. En el año 1956, como digo, regresaron a España y es cuando empecé a desarrollar mi español.

\section{¿Entonces qué representa para usted la lengua rusa?}

Aunque sea una pregunta breve la respuesta me costaría mucho tiempo, forma parte de mi expresión, y aunque mi lengua habitual es el catalán, que también traduzco al castellano, sin embargo, el ruso, como mi lengua de la infancia con los estudios posteriores para mí, es lengua hermana del español y el catalán, y en este sentido se iguala a una y a otra.

\section{¿Desde hace cuánto traduce? ¿Cuál fue su primera traducción?}

Traduzco de los años setenta y mi primera traducción fue Corazón de perro de Bulgákov, en una pequeña editorial barcelonesa, publicada en los principios de los setenta. En 1978 viajé a la Unión Soviética con el objetivo de perfeccionar el idioma ya que asumí pronto que la tarea del traductor habría que ser mi modus vivendi tras entrar en la Universidad, y así compaginé mi docencia Universitaria con las traducciones.

¿Qué otras obras de autores rusos ha traducido?

Traduje El Pabellón número 6 de Chéjov. También traduje a Pushkin, fragmentos y algunos 
506 textos de Dostoievski; así mismo a Tolstoi y otros autores rusos del siglo XX, desde Brodski a Dovlatov, e incluso a autores más modernos. Entre lo último que he traducido se encuentra la obra de Bábel Caballería roja.

¿Cómo llegaron los libros de Svetlana Aleksiévich a sus manos?

Pues, por revistas, por agentes... Recuerdo que la editorial Casiopea se interesó por el libro, aunque yo conocía a Aleksiévich de antes, de otras publicaciones entorno al año 1996, una década después de la tragedia de Chernóbil. He hecho distintas aproximaciones en la traducción de Chernóbylskaia molitva, como La plegaria o Voces de Chernóbil.

¿Hay diferencias reseñables entre traducir a Svetlana Aleksiévich y otros escritores rusos?

Una fundamental es que la oralidad está constantemente presente en el texto de Svetlana. Y eso permite más juego, como la utilización de distintos sinónimos, ya que no son textos aferrados a la letra impresa, sino que han surgido de las voces y los testimonios orales. Pero, por otro lado, también es cierto que es más complejo traducir un texto que vive, en estas características por tener un origen en esa expresión oral. No se trata de un texto que la escritora haya trabajado internamente o meditado, aunque sí, corregido y revisado una vez escrito. Pienso que esta es la mayor diferencia con respecto a otros autores, en los que se plantean problemas de una diferente índole textual. Por ello está claro que en esta obra de Aleksiévich si la oralidad permite un mayor margen de libertad, por otro lado, exige una interpretación muy precisa, ya que lo que se traduce que puede haber sido dicho por una persona que estaba allí, tal vez, junto a un pobre bombero moribundo, lleno de radiación. En la mayoría de los casos, la expresión está llena de sentimientos, lo que a su vez, exige al traducir moverse en estos para expresarlos lo más fiel posible en otra lengua; un hecho que considero de los más complejos de la tarea de traducción.

Recuerdo también la traducción del escritor Shalámov en la cual resultaba doloroso manejar su dimensión estética unida a la enorme dimensión humana de lo que trataba en su obra. La cuestión es tratar un material muy vivo, mientras con la traducción se traslada como una experiencia narrada de una lengua a otra. Esta construcción estética que en el caso del autor está perfectamente trabada, en el caso del traductor es casi como una intromisión. Provoca incomodidad. Los textos de Shalámov son carne viva. En cambio, con los escritores como Bábel, que optan abiertamente por una actitud estética, el traductor puede estar más cómodo.

¿Ha podido establecer una relación amistosa, más allá de la estrictamente profesional, con Aleksiévich? ¿Ha solicitado su parecer durante la traducción del libro?

Sí, la verdad es que le escribí bastantes veces. Nos hemos visto siempre que ha venido a Barcelona. Justamente hoy estaba leyendo una última entrevista que ha sometido a la revista Novyi Zhurnal, que se publicó en 2018. Es una persona realmente entrañable, además de hacerse visible al habar con ella su gran inteligencia y sensibilidad.

¿Cuál es su criterio sobre la obra de Svetlana Aleksiévich y dónde la situaría en el conjunto de la literatura rusa actual?

Su obra es un hecho insólito, aunque se percibe nítidamente dentro de aquellas voces de la URSS que aparecían en distintos formatos. Desde el final y el hundimiento de la URSS, también aparecieron otros escritores en cuya obra lo do- 
cumental constituye un papel muy importante, así el mismo Shalámov citado. Posiblemente, a partir de aquellos momentos y de la desintegración la desintegración de la Unión Soviética, se produce un fenómeno literario en el que ella se anticipa al resto de autores: trabajaba de ver con nuevos ojos la realidad que había sido el gran sueño de una gran parte de la población soviéticas. De hecho, fue un gigantesco proyecto lanzado hacia el futuro, pero cuando este futuro desapareció, la gente se planteó la necesidad de reflexionar sobre el pasado e incluso de reescribirlo en la mayoría de los casos. Hablamos de todas esas personas que construyeron su vida desde la perspectiva de un futuro mejor. Es decir, han sufrido y han realizado en muchos casos trabajos inhumanos en nombre de un futuro que desapareció. Eso obligó, y de ello es la prueba Aleksiévich, a reflexionar dejando el testimonio de esta experiencia. De ahí que la memoria o la voz de quien ha vivido estas experiencias jueguen un papel tan decisivo.

La autora hereda la escritura de Adamóvich y Granin, dos escritores que plantearon en su momento, con el libro Blokadnaya kniga, que recoge testimonios, de gente que ya difícilmente podía hablar, para dejar su voz plasmada en la escritura. Lo mismo ocurrió con el libro de Aleksiévich sobre Afganistán y los suicidios. La autora en sus conversaciones buscaba en las ancianas el recuerdo de la guerra, convirtiéndose en su voz.

Hay una tendencia en los escritores rusos en utilizar el documental para crear obras memorialísticas y así mostrarnos las experiencias que desaparecen. Recuerdo una entrevista que leí sobre Chernóbil: «nosotros desaparecemos, nuestros recuerdos desaparecerán, pero Chernóbil seguirá allí».

¿Cómo suele afrontar la tarea de traducir una obra literaria? ¿Cómo ve las principales características que deban definir la función del traductor literario

y cuáles entiende que son mayores dificultades a las que se enfrenta?

Últimamente trabajo el libro si este me interesa, aunque antes cogía solo lo que podía, pues dependía de las clases, de otros proyectos... Si es un escritor en prosa, me interesa bastante, también lo memorialístico, los relatos escritos en primera persona, que en su momento tuvieron un gran éxito y que hoy podría volver para traducirlos. En varios casos lo he hecho. En general he aceptado proyectos que me interesaron personalmente o bien yo mismo he propuesto estos proyectos.

Hay muchos espacios vacíos, белые пятна (belye piatna), muchas grandes obras que todavía no se han traducido al castellano o que no se han visto dignamente representadas en español. Creo que no son difíciles de encontrar. Y bueno, ya que estoy a punto de jubilarme, lo tomo con cierta tranquilidad. Estoy dándole vueltas a la posibilidad de traducir a Zóschenko, que hace mucho tiempo que no se ha traducido. Yo traduje uno de sus libros, pero su humor, como ocurre con la poesía, es muy difícil de tratar en la traducción. Otras obras de Zóschenko, Голубая книга (El libro azul), Перед восходом солнца (Antes del amanecer), son enormemente inquietantes y tendría sentido que vieran la luz para recuperar su tradición satírica y grotesca, aunque la verdad es que los suyos textos presentan como una cierta dificultad a la hora de ser traducidos.

Ahora me muevo por lo que me atrae en cada momento. Si Svetlana acabara su libro sobre el amor, tal vez me gustaría traducirlo, cosa que me parece ya improbable. Por otro lado, los editores siempre quieren el libro para mañana, $y$ yo la verdad, es que tampoco puedo traducir con urgencia. Sin duda hay muchas publicaciones que 
508 se me escapan, pero si aparece algo interesante, y no tengo límite de tiempo, suelo aceptarlo.

¿La labor del traductor se centra sólo en traducir palabras o debe interpretar?

La función de la traducción es acercar las culturas. Hay que saber por lo menos qué es un «самовар» (samovar) о la palabra «изба» (isbà), y poder visualizar una casa de madera con techo de paja de un campesino ruso poco menos que miserable. Mis estudiantes deben saber visualizar la realidad que nos transmiten Tolstói, Chéjov, Dostoievski, y de la civilización soviética, tienen que entender conceptos absolutamente desconocidos en nuestra cultura. Hay que tener en cuenta que el idioma ruso o el vocabulario soviético, abarca unos aspectos muy particulares. El traductor tiene que colaborar con el autor, saber interpretar bien su trabajo y poder trasmitir la realidad rusa al castellano en el caso que nos ocupa.

Cuando usted hizo su primera traducción de Svetlana Aleksiévich, no había versiones de sus libros en español. ¿Cuál fue su primera impresión al leerlos? ¿Quépensó sobre ellosy sobre los temas que la autora trataba?

Cuando escribí a Svetlana, me mandó dos tomos color gris que tenía, donde aparecían otras obras ya publicadas en 1986, o quizás fue más tarde, no lo recuerdo, pero fue a partir de un escrito mecanografiado que ella me envió y que tenía correcciones; cuando realmente me interesó y me impresionó mucho, porque siempre te sobrecoges oyendo una voz a través de los escritos de Svetlana. Lo primero que me impresionó fue eso: la inmediatez del texto, la oralidad que desprendía el texto.

Cuando algunas palabras rusas no tienen correspondencia con el español, ¿adopta soluciones «domesticantes» o «extranjerizantes»? ¿Cuál es su actitudy su criterio acerca del uso de las palabras que no están en ruso, sino en bielorruso o en ucraniano?

Selo preguntaba a la gente que sabía bielorruso o ucraniano, pero no recuerdo que tuviera problemas de este tipo en el texto. Sí preguntaba alguna expresión científica, más que nada, relacionada con la energía atómica, igual que con las expresiones cariñosas y sentimentales que siempre intentaba adaptar al castellano. Pero en cualquier caso, me inclino más por aproximar el texto, en la medida de lo posible, a la lengua de destino y no introducir nada nuevo. A veces no hay remedio, como en los textos de Shalámov, donde aparecían expresiones que tenías que inventarte, comо «доходяга» (dojodiaga). Pero depende del contexto, hay palabras que uno deja en ruso y dentro del mismo texto se van explicando. Para otras buscas soluciones, como en el caso «доходяга» (dojodiaga), que si «terminal», «desahuciado»... Pero, evidentemente, son expresiones que se refieren a realidades inexistentes en la lengua de destino. Aunque no soy muy partidario de las notas, en ocasiones es necesario incluirlas, como algún extranjerismo o alguna expresión o anglicismo, pero intento siempre acercarme lo máximo posible para que el lector pueda entender el texto sin una gran dificultad en la lengua del destino.

¿Qué le ha parecido el texto de las Voces de Chernóbil desde el punto de vista lingüistico? ¿Le ha supuesto algún problema los coloquialismos de los diálogos (por ejemplo: «xaта» (jata), «бабка» (babka), «хозяин» (josianin) - в значении муж (v znachenii muzh))? ¿Quédificultades le han dado?

Intenté traer expresiones que pudieran dar al lector una aproximación al término, aunque perdieran parte de su valor. Por ejemplo, 
términos como «хозяин» (josianin) - в значении муж ( $v$ znachenii muzh) («el amo» en sentido del marido) dependen de si se entienden en el propio discurso. En este sentido, Svetlana me ayudó bastante, así como otras personas que sabían ruso y bielorruso. Yo creo que mi gran problema en las traducciones son aquellas cosas que tú crees que has entendido, pero que no has entendido, y eso sí que difícilmente se puede resolver. Bueno, la solución es que otro traductor vuelva a hacer esa traducción.

Respecto de la corrección del texto de Svetlana, me apoyé en la nueva edición de su libro que se publicó a raíz de conseguir el Premio Nobel y de su éxito inicial. La primera edición fue en Casiopea, luego en Siglo XXI y ahora en Debate y Debolsillo. Cada edición me permitía volver al texto y revisarlo en beneficio del propio discurso en castellano. Por otro lado, siempre había correcciones de la propia autora, acerca de erratas de la edición rusa inicial; en fin, es otra de las ventajas de la retraducción y de la revisión. En este caso coincidió con tres ediciones que me permitieron revisar repetidamente el texto. Me ayudó más que a los primeros traductores que tuvieron que traducir de prisa la mayoría de las obras de Svetlana después del Premio Nobel para aprovechar el boom y la fama. En catalán ha sido la cosa más tranquila, y no hace mucho apareció la versión catalana de La guerra no tiene rostro de mujer. Se lo han tomado con más calma, pero las traducciones castellanas creo que han pecado de esta urgencia, que esperemos que se pueda resolver en nuevas ediciones.

En la versión traducida al español de Voces de Chernóbil se encuentran numerosos elementos de humor, como una especie de chistes, traídos con cierto sarcasmo por los entrevistados. Considero que traducir la cultura autóctona de un pueblo, también a través de la ironía, debe ser algo complicado. ¿Cómo 509 afronta este reto?

El humoryla poesía es lo más difícil de traducir. Me acuerdo de lo último: «la Meca del átomo», aquellas excursiones que se organizaban para visitar Chernóbil. Más que un chiste parecía un sarcasmo. Uno intenta interpretar lo mejor posible este juego de sentidos que trae la ironía y el dramatismo que suele acompañar al sarcasmo.

¿Suele adoptar la traducción a la cultura de llegada o se atreve con otras estrategias?

Depende del caso. Al principio siempre hay que mantener una cierta proximidad, no podemos convertir a un «мужик» (muzhik) en un «campesino». Yo lo traduzco como muzhik. Pero hay otros términos que se pueden aproximar a tu propia lengua. Si es una «pala», pues empleo «pala», que se da en todas las lenguas. Pero ciertas ideas que no se dan en tu propia lengua, en un texto traducido hay que mantenerlas.

¿Considera la utilidad de poner notas explicativas a pie de página? ¿Qué opinan de ello sus editores?

Como he comentado antes, los editores me han mantenido las notas en mis traducciones aunque algunos de ellos insisten en eliminarlas. En el caso de Voces de Chernóbil sí que había ciertos tecnicismos que exigían poner notas al pie y explicar lo que es un «becquerel», por ejemplo. Es algo obligado que el editor lo mantenga. Creo que hay palabras técnicas que es mejor dejarlas en el texto para que el lector pueda entender todo lo relacionado con el campo de la radiación, de las realidades atómicas, etc, en este caso me informé detenidamente en relación a este tema. Incluso apareció un estudio publicado en ese tiempo tratando aquella tragedia desde un 
510 punto de vista especializado, a propósito de los problemas técnicos.

¿Qué opinión tiene sobre el resultado final de su traducción de Voces de Chernóbil?

Esto que me pregunta no me correspondería contestarlo yo, sino los lectores. Una traducción siempre es mejorable. Es decir, con una traducción hablamos de un texto de segunda mano, y permanentemente hay que continuar la actividad traductora. Por propia experiencia, en cada revisión se encuentran elementos que pueden mejorarse, pero también empeorase. No obstante, en todo, siempre se busca descubrir errores de los que no habías sido consiente para optimizar la traducción.

\section{RECURSOS ELECTRÓNICOS CONSULTADOS}

Universidad de Barcelona, (2018): Ricardo San Vicente se despide de las aulas de la Universidad de Barcelo$n a$, https://www.ub.edu/web/ub/es/menu_eines/ noticies/2018/05/063.html, [fecha de consulta: $10 / 12 / 2018]$

Universidad de Barcelona, (2015): Ricardo San Vicente: "El hombre soviético no ha desaparecido todavía", https:/www.ub.edu/web/ub/es/menu_eines/noticies/2015/entrevistes/sanvicente.html, [fecha de consulta: 03/01/2019] 